\title{
High Concentrations of Unidentified Extractable Organofluorine observed in Blubber from a Greenland Killer Whale (Orcinus orca)
}

\author{
Lara Schultes $^{1 \# *}$, Carmen van Noordenburg ${ }^{1 \#, ~ K y r a ~ M . ~ S p a a n ~}{ }^{1}$, Merle Plassmann ${ }^{1}$, Malene Simon $^{2}$, Anna Roos $^{2,3}$, \\ Jonathan P. Benskin ${ }^{1 *}$ \\ 1 Department of Environmental Science, Stockholm University, Stockholm, Sweden \\ 2 Greenland Climate Research Center, Greenland Institute of Natural Resources, Nuuk, Greenland \\ 3 Department of Environmental Research and Monitoring, Swedish Museum of Natural History, Stockholm, Sweden
}

\begin{abstract}
It is generally accepted that per- and polyfluoroalkyl substances (PFASs) occur primarily in protein-rich tissues such as blood and liver, but few studies have examined the occurrence of PFASs (in particular emerging PFASs), in lipid-rich tissues such as blubber. Here we report the distribution of 24 PFASs, total fluorine (TF) and extractable organic fluorine (EOF) in eight different tissues of a killer whale (Orcinus orca) from East Greenland. The sum of target PFAS concentrations was highest in liver $(352 \mathrm{ng} / \mathrm{g} \mathrm{ww})$ and decreased in the order blood $>$ kidney $\approx$ lung $\approx$ ovary $>$ skin $\approx$ muscle $\approx$ blubber. Most of the EOF was made up of known PFASs in all tissues except blubber, which displayed the highest concentration of EOF, almost none of which was attributed to targeted PFASs. Suspect screening using high-resolution mass spectrometry revealed the presence of additional PFASs but the magnitude of peak areas could not explain the high concentrations of EOF in blubber. While the identity of this unknown organofluorine and its pervasiveness in marine mammals requires further investigation, this work suggests that exposure of killer whales to organofluorine substances may be underestimated by determination of legacy PFASs exclusively in liver tissues.
\end{abstract}

\section{INTRODUCTION}

Per- and polyfluoroalkyl substances (PFASs) are a class of mostly anthropogenic chemicals which occur globally in biotic and abiotic media. ${ }^{1-3}$ Most PFAS research has focused on less than 50 substances, which can be broadly classified as either perfluoroalkyl acids (PFAAs), PFAAprecursors, or alternatives (e.g. fluoroether-based substances). ${ }^{4}$ However, a recent report by the OECD has indicated that these substances represent a small fraction of the 4730 PFAS-related CAS numbers in commerce worldwide. ${ }^{5}$ While it is unclear what fraction of these substances are environmentally relevant, several studies have identified the presence of novel PFASs in wildlife with the help of high resolution mass spectrometry (HRMS)-based non-target and suspect screening techniques. ${ }^{6-8}$

A complementary approach to both targeted and nontarget analysis involves determination of total and extractable organic fluorine (TF and EOF, respectively). ${ }^{9}$ By combining these data, the total quantity of (organo) fluorine substances can be estimated. This so-called fluorine mass balance approach has been demonstrated in wildlife, disclosing major fractions of unidentified organic fluorine that were not accounted for by target PFAS analysis. ${ }^{10-12}$ Collectively, these studies suggest that environmental exposure of wildlife to PFASs is often underestimated.
Arctic top predators are sentinel species for persistent organic pollutants (POPs). ${ }^{13}$ POPs can be transported to high latitudes via oceanic currents or through the atmosphere. The killer whale (Orcinus orca) is a mammalian apex predator of the marine food web, and thereby burdened by high loads of contaminants which may pose a threat to their health. ${ }^{14-16} \mathrm{~A}$ recent study reported the first observation of F53B, a metal plating mist suppressant, manufactured and used solely in China, in killer whales, polar bears and ringed seals from Greenland, demonstrating the long-range transport potential of this pollutant. ${ }^{17}$ While the occurrence of PFASs in top predators is strongly influenced by diet and feeding habits, speciesspecific biotransformation may also play a role. For example, cetaceans tend to lack the enzymes necessary to biotransform PFAA-precursors. ${ }^{18,19}$ Consequently, certain PFAA-precursors (e.g. perfluorooctane sulfonamide (FOSA)) tend to occur at elevated concentrations in these animals. There are few data on the tissue distribution of these substances, and even fewer data on non-legacy PFASs, such as aromatic or mixed-halogen PFASs. Given the diverse physico-chemical properties contained within the large class of PFASs, we hypothesized that certain organofluorine substances may accumulate in tissues other than the protein-rich liver or blood tissues and are

\footnotetext{
* Corresponding authors: lara.schultes@gmail.com, jon.benskin@aces.su.se

\# These authors contributed equally to this work
} 
inevitably overlooked by focusing on targeted PFAS analysis in liver.

To test this hypothesis, we quantified 24 PFASs as well as TF and EOF in eight different tissues of a killer whale from East Greenland. Additionally, HRMS-based suspect screening was carried out to identify untargeted and novel PFASs. To the best of our knowledge this is the first time the tissue distribution of $\mathrm{TF}$ and $\mathrm{EOF}$ have been investigated in a marine mammal.

\section{MATERIALS AND METHODS}

\section{Sample collection and extraction}

Sampling was carried out together with local subsistence Inuit hunters in Tasiilaq, East Greenland, in 2017. A total of eight different tissues (blood, blubber, kidney, liver, lung, muscle, ovary and skin) were subsampled from a female killer whale. EOF, TF, suspect and target PFAS data were reported previously in liver from this individual as part of a survey in marine mammals from the North Atlantic. ${ }^{8}$ Samples were shipped frozen in individual polypropylene (PP) tubes to the Swedish Museum of Natural History and thereafter to Stockholm University for extraction and analysis. Further information on sampling is provided in the supporting information (SI).

Sample extraction for targeted analysis and suspect screening was carried out on $0.5 \mathrm{~g}$ portions of tissue $(n=3$ replicates/tissue). Tissues were thawed at room temperature prior to extraction and then fortified with $1 \mathrm{ng}$ of individual internal standards (ISs). Extraction was carried out using acetonitrile together with bead blending (see SI for details). Following extraction, $500 \mu \mathrm{l}$ of each extract was mixed with $500 \mu \mathrm{l}$ of $4 \mathrm{mM}$ aqueous $\mathrm{NH}_{4} \mathrm{OAc}$ and fortified with two recovery standards (1 ng each), prior to instrumental analysis.

Sample extraction for EOF was carried out on $0.5 \mathrm{~g}$ portions of tissue ( $n=3$ replicates/tissue) using the aforementioned extraction procedure for targeted analysis, but without addition of ISs and buffer. Following clean-up, the extract was split into two equal portions, which were each concentrated to $100 \mu \mathrm{l}$ prior to instrumental analysis. TF measurements were performed directly on unextracted tissue material (i.e. without sample preparation; $0.1 \mathrm{~g}, \mathrm{n}=3$ replicates/tissue).

\section{Instrumental analysis}

Targeted PFAS analysis was carried out on an Acquity ultra-high-performance liquid chromatograph (UHPLC; Waters) coupled to a Xevo TQ-S triple quadrupole MS (Waters). Extracts were chromatographed on a C18 bridged ethylene hybrid column $(50 \times 2.1 \mathrm{~mm}, 1.7 \mu \mathrm{m}$; Waters). Details on instrumental parameters can be found in the SI.

EOF and TF were analyzed following published methods $^{820}$ (see SI for details). Briefly, samples (100 $\mu 1$ for extracts, $100 \mathrm{mg}$ for neat material) were combusted at $1000^{\circ} \mathrm{C}$ with oxygen as combustion gas and argon as carrier gas (HF-210, Mitsubishi). Combustion gases were adsorbed into water (GA-210, Mitsubishi) and analyzed with an ion chromatograph (Dionex, Thermo Scientific).

Suspect screening was carried out using a Dionex Ultimate 3000 UHPLC coupled to a Q Exactive HF Orbitrap HRMS (both Thermo Scientific), as described previously. ${ }^{8,21}$ The Orbitrap was operated in negative ionization, full scan mode (resolution of 120000 full width at half maximum (fwhm) at $200 \mathrm{~m} / z$ ) with data dependent MS/MS acquisition (resolution of $15000 \mathrm{fwhm}$ at $200 \mathrm{~m} / \mathrm{z}$ ) for substances on an inclusion list. See SI for details.

\section{Target PFASs}

A full list of natives, ISs and recovery standards can be found in Table S3 of the SI. For the 24 target PFAS, two levels of data quality were defined based on the availability of native and mass-labeled standards (see SI for details and a full list of abbreviations). Branched and linear isomers of FOSA, PFOS and PFDS are reported as summed concentrations in the main text, and summed branched concentrations are reported in the SI.

\section{Quality assurance and quality control}

UHPLC-MS/MS. Replicate spike-recovery experiments were carried out to assess the accuracy and precision of the analytical method on each of the 8 tissues types. Briefly, authentic PFAS standards (5 ng each; with the exceptions of PFOS in liver (200 ng) and kidney (60 ng)) were fortified into tissue samples and extracted in triplicate as described above. Extraction blanks were analyzed with every batch. During UHPLC-MS/MS analysis, solvent blanks and QCs were run intermittently to monitor carry-over and instrument stability, respectively. Due to the absence of analytes in the blanks, limits of detection (LODs) were based on the lowest calibration standard with a signal-to-noise ratio of 3. Compoundspecific method detection limits (MDL) were calculated using the LOD and an average sample amount $(0.5 \mathrm{~g})$, and are reported in Table S3. External validation of the method was performed by analysis of a NIST standard reference material (SRM 1957, Organic Contaminants in NonFortified Human Serum).

CIC. We previously demonstrated that inorganic fluorine was efficiently removed from liver and that PFOS (as a surrogate for PFASs) was efficiently recovered using the acetonitrile-based extraction procedure employed here. ${ }^{8}$ In the present work, additional spiking experiments were performed to confirm these findings in the remaining tissues by fortifying each tissue ( $n=3$ replicates per tissue) with a mixture of PFOS (250 ng) and $\mathrm{NaF}$ (500 ng). The MDL for EOF was based on the average fluorine concentration in the extraction blank plus the standard deviation of the triplicate extraction blanks. Accuracy and precision of TF measurements were assessed by triplicate 
analysis of a certified reference material (CRM, BCR-461 fluorine in clay). The MDL was based on the average instrumental blank plus standard deviation, and converted using an average sample amount $(0.1 \mathrm{~g})$.

\section{Data handling}

For the purpose of fluorine mass balance calculations, individual PFAS concentrations ( $\mathrm{C}_{\mathrm{PFAS}}$ ) were converted to fluorine concentration equivalents $\left(\mathrm{C}_{\mathrm{F}_{-} \text {PFAS }}\right)$ using their molecular fluorine percentage (see SI for details). EOF concentrations $\left(\mathrm{C}_{\mathrm{F}_{-} \mathrm{EOF}}\right)$ were corrected using the average tissue-specific PFOS recovery (obtained from tissuespecific spike-recovery experiments; Table S7) for comparability with $\Sigma \mathrm{C}_{\mathrm{F}_{-} \mathrm{PFAS}}$ concentrations. Total fluorine concentrations $\left(\mathrm{C}_{\mathrm{F}_{-} \mathrm{TF}}\right)$ were used without further adjustment. High resolution MS data were processed using Compound Discoverer 3.0 and further inspected using Xcalibur (Thermo Fisher Scientific). Individual features were searched against a list of suspect PFASs identified in liver from this Killer whale reported previously. ${ }^{8}$ A 5-point confidence level (CL; Figure 3) scale was assigned to suspect PFASs, depending on data availability. ${ }^{22}$ Suspect peak areas were only reported when observed in all three tissue replicates. Thereafter, peak areas were averaged, and divided by the tissue-averaged M8PFOS response.

\section{RESULTS AND DISCUSSION}

\section{Method performance}

UHPLC-MS/MS. Target PFASs were below MDLs in all blanks. Most compounds displayed good IS-corrected recoveries across all tissues (average $80-120 \%$, Table S4), with the exceptions of PFTeDA, PFDS, 9Cl-PF3ONS and 11Cl-PF3OUdS, which displayed higher recoveries (161$235 \%$ ), as well as 3:3 and 5:3 FTCA which displayed lower recoveries (35-65\%), most likely due to the lack of exactly matched ISs for those substances. Reported concentrations for these compounds should therefore be regarded as semiquantitative. Precision, assessed via the relative standard deviation (RSD) of triplicate spiked samples, averaged $7.3 \%$ over all tissues and compounds (Table S4). Finally, external validation of the method through analysis of SRM 1957 revealed good consistency between measured and reference concentrations for most compounds (Table S5).

CIC. PFOS spike-recovery experiments using surrogate liver averaged $68.5 \%$ over all concentration levels, with a precision of $2.5 \%$ RSD. Inorganic fluorine was removed efficiently at all spiking levels (Table S6). Recovery of spiked PFOS from individual tissues averaged $66 \%$ (10\% RSD; Table S7). Notably, EOF in liver reported here is slightly higher than reported in Spaan due to small (yet non-significant) differences in \% recoveries used to correct EOF concentrations (mean \pm RSD of $65 \pm 5 \%$ in the present work versus $69 \pm 3 \%$ in Spaan et al. ${ }^{8}$ ) Triplicate analysis of the CRM revealed excellent accuracy and precision of TF measurements (measured: $541 \pm 8 \mathrm{mg} / \mathrm{kg}$, certified $568 \pm 60 \mathrm{mg} / \mathrm{kg}$ ).

\section{Tissue distribution of target PFASs}

The highest $\Sigma_{24}$ PFAS concentration occurred in liver $(352 \pm 101 \mathrm{ng} / \mathrm{g} \mathrm{ww})$, which is fairly consistent with measurements in killer whale livers $(n=6)$ from the same location reported previously $(269 \pm 90 \quad \mathrm{ng} / \mathrm{g} \quad \mathrm{ww}){ }^{17}$ Concentrations in blood, lung, kidney and ovary were similar to one another but lower than liver (range $82 \pm 19$ to $116 \pm 21 \mathrm{ng} / \mathrm{g} \mathrm{ww}$; Figure 1, Table S8). Muscle, skin and blubber contained the lowest $\Sigma_{24}$ PFAS concentrations ( $9.5 \pm 5.7$ to $19 \pm 4.3 \mathrm{ng} / \mathrm{g}$ ww; Figure 1 , Table S8). A similar tissue distribution pattern for $\Sigma$ PFAS concentrations was reported in polar bears from East Greenland, ${ }^{23}$ and arctic fox from Svalbard, Norway, ${ }^{24}$ while harbor seals from Germany and the Netherlands displayed the highest PFAS concentrations in blood and kidney. ${ }^{2526}$ Despite some differences, the aforementioned studies all reported highest PFAS concentrations in protein-rich tissues. This pattern is hypothesized to originate from the highly specific binding of PFAAs to proteins (mainly serum albumin, liver fatty acid binding proteins and organic anion transporters), as well as their interactions with phospholipids. ${ }^{27,28}$ These interactions are based on the ionic nature of PFAAs, whereas the partitioning behavior and other binding mechanisms of neutral and volatile PFASs are scarcely studied.

Among individual PFASs, PFOS was dominant in all tissues, followed by PFUnDA and PFTrDA. The overall PFAS profile was fairly consistent across tissues with a few exceptions. For example, kidney, muscle and blubber showed higher percentages of FOSA, while PFUnDA was higher in liver and blood. 7:3 FTCA was also observed exclusively in liver (13.7 ng/g ww) and blood (4.6 ng/g ww). Several studies have reported the occurrence of $7: 3$ FTCA in wildlife and humans, ${ }^{10,29-32}$ with particularly high concentrations observed in polar bear livers from East Greenland. ${ }^{8}$ To the best of our knowledge this is the first report of the tissue distribution of 7:3 FTCA in a marine mammal. Long-chain PFCAs (C7-C13) were detected in all tissues with concentrations decreasing with decreasing chain length. Odd-chain PFCA homologues tended to occur at higher concentrations compared to their adjacent even-chain homologues, as reported previously. ${ }^{33}$ Short chain PFCAs (PFBS, PFPeA, PFHxA and PFHpA) were detected in relatively low concentrations in several tissues (Table S8).

\section{Fluorine mass balance}

EOF was measurable in 6 tissues $(<\mathrm{MDL}$ for ovary and skin; Table S8) and displayed a strong linear correlation with $\Sigma_{24}$ PFAS concentrations for all tissues except blubber $\left(r^{2}=0.9391\right.$; Figure 2$) . \Sigma C_{F_{-} P F A S}$ was not significantly lower than $\mathrm{C}_{\mathrm{F}_{-} \mathrm{EOF}}$ in liver, blood, lung and kidney, essentially 
accounting for EOF in most tissues (Figure 2). The exception was for blubber, where only $2.7 \pm 0.4 \%$ of the EOF was identified from target PFASs. This is remarkable considering that blubber contained the lowest $\Sigma_{24}$ PFAS concentrations, and PFASs are generally considered lipophobic, and therefore are not expected to accumulate in lipid-rich tissues.

The highest concentrations of TF were observed in blubber, lung and kidney (Figure 2). With the exception of liver, EOF accounted for $<20 \%$ of $\mathrm{TF}$, leaving major fractions of TF unidentified. $\Sigma C_{F_{-} \text {PFAS }}$ accounted for only $0.5 \pm 0.1 \%$ (blubber) up to $27.7 \pm 3.2 \%$ (ovary) of TF. In liver, however, the fluorine mass balance was almost closed, with EOF accounting for $48.4 \pm 3.8 \%$ of the TF, and $\Sigma \mathrm{C}_{\mathrm{F}_{-} \mathrm{PFAS}}$ accounting for $122.6 \pm 22.3 \%$ of the EOF. Since most known PFASs (e.g. PFCAs and PFSAs) accumulate in liver, this result is not necessarily surprising. However, the large gap in the fluorine mass balance in blubber is unexpected and points to the occurrence of large quantities of unidentified lipophilic organofluorine substances (or inorganic fluorinated substances in the case of TF).

\section{HRMS suspect screening}

A heatmap showing the relative abundance of 17 target and 19 suspect PFASs in each tissue is provided in Figure 3 . Suspect PFASs in liver from this animal were previously reported ${ }^{8}$ but the tissue distribution is reported here for the first time. The observation of perfluorononane sulfonamide (FNSA) is particularly notable since this substance displayed the highest response in blubber. However, assuming equivalent matrix effects across tissues (which requires confirmation with authentic standards), absolute peak areas of FNSA in blubber were deemed too low to explain the unknown EOF in blubber. Thus, we conclude that the 19 suspect PFASs reported here do not account for the unknown EOF in blubber.

\section{IMPLICATIONS}

This study revealed, for the first time, the presence of large amounts of unidentified EOF in killer whale blubber. Killer whale blubber is known to contain high concentrations of legacy and novel chlorinated POPs, ${ }^{16,34,35}$ but little is known about the occurrence of fluorinated chemicals in these tissues. While several suspect PFASs were detected in blubber from the present work (among other tissues), these are unlikely to explain the large amount of unidentified EOF. Future work will focus on applying GC-based MS detection methods which may be more successful at measuring lipophilic fluorinated substances in blubber.

\section{ACKNOWLEDGMENT}

We are very grateful to subsistence hunter Mathane Qatsa for collaborating in sampling. Financial support from the was provided by the Swedish Research Council FORMAS (Grant number 2013-00794). Dr. Vladimir Nikiforov and Dr. Nicholas Warner (NILU) are thanked for helpful feedback on this manuscript. 

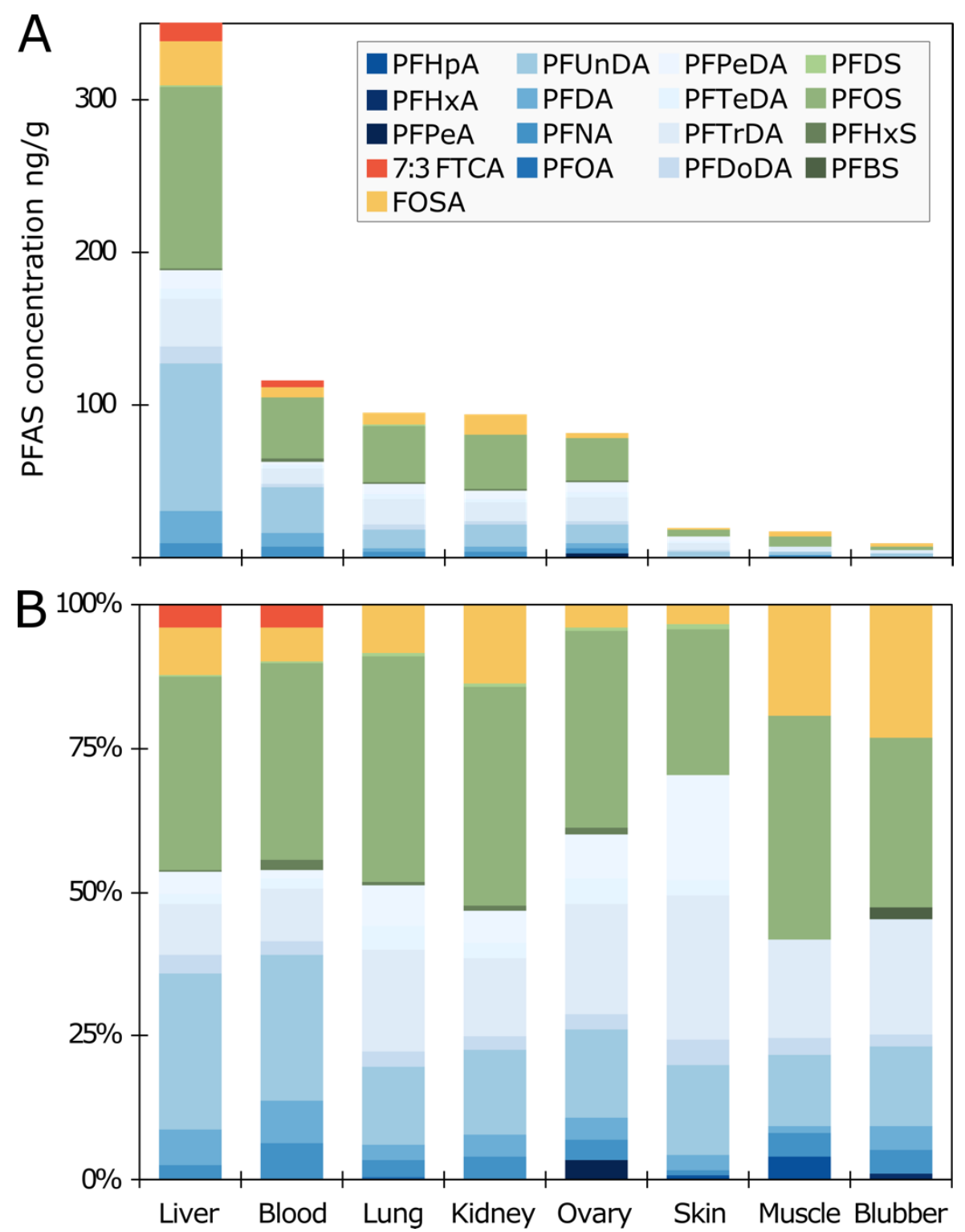

Figure 1. PFAS concentrations in killer whale tissues, A) in $\mathrm{ng} / \mathrm{g}$ ww and B) as relative pattern. 

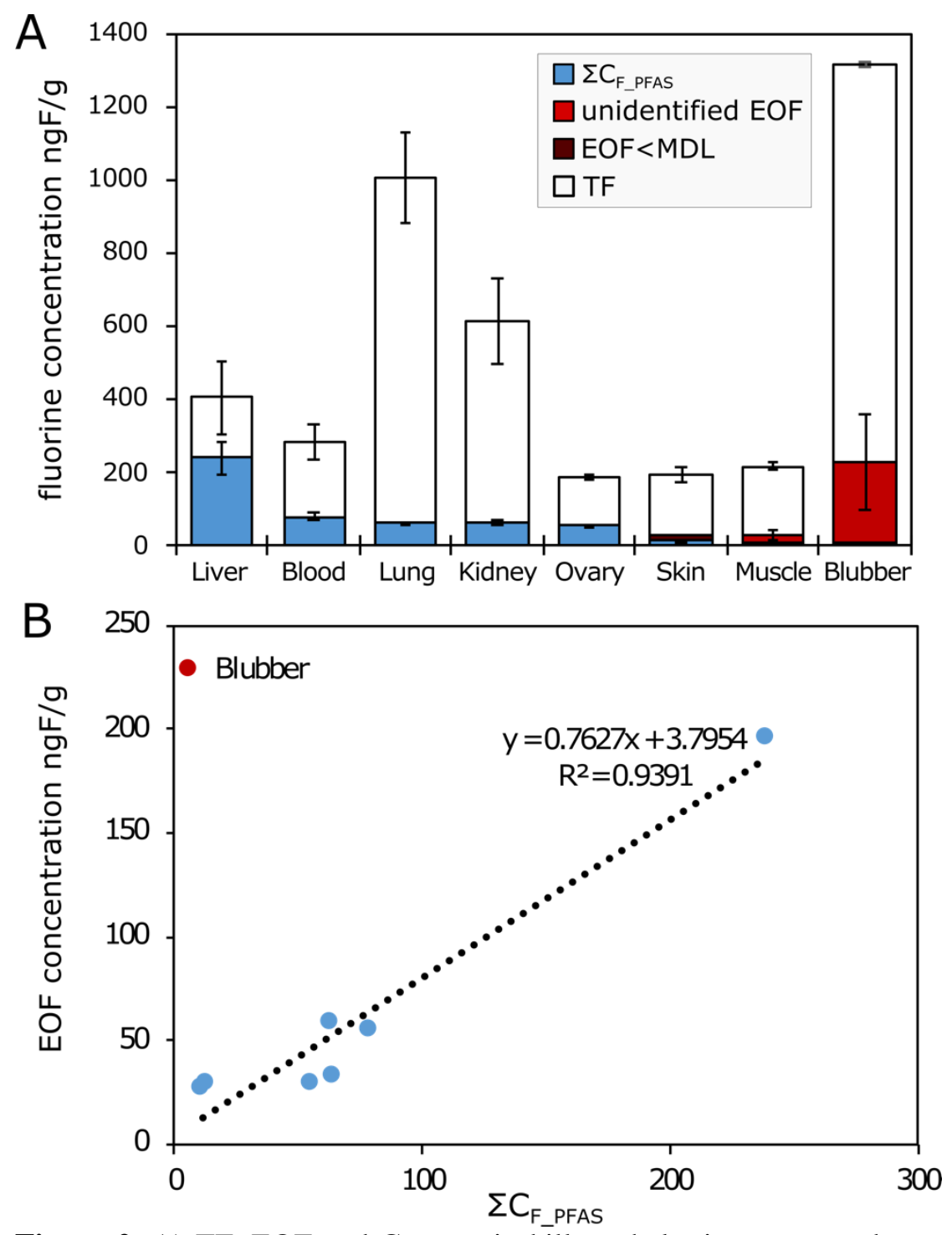

Figure 2. A) TF, EOF and $\mathrm{C}_{\mathrm{F}_{-} \Sigma \mathrm{PFAS}}$ in killer whale tissues: error bars represent standard deviation from duplicate measurements (TF, EOF) or triplicate extractions $\left(\mathrm{C}_{\mathrm{F}_{-} \Sigma \text { PFAS }}\right)$. B) Correlation of EOF and $\mathrm{C}_{\mathrm{F}_{-} \Sigma \text { PFAS. }}$. The regression equation and correlation coefficient were calculated without blubber. 


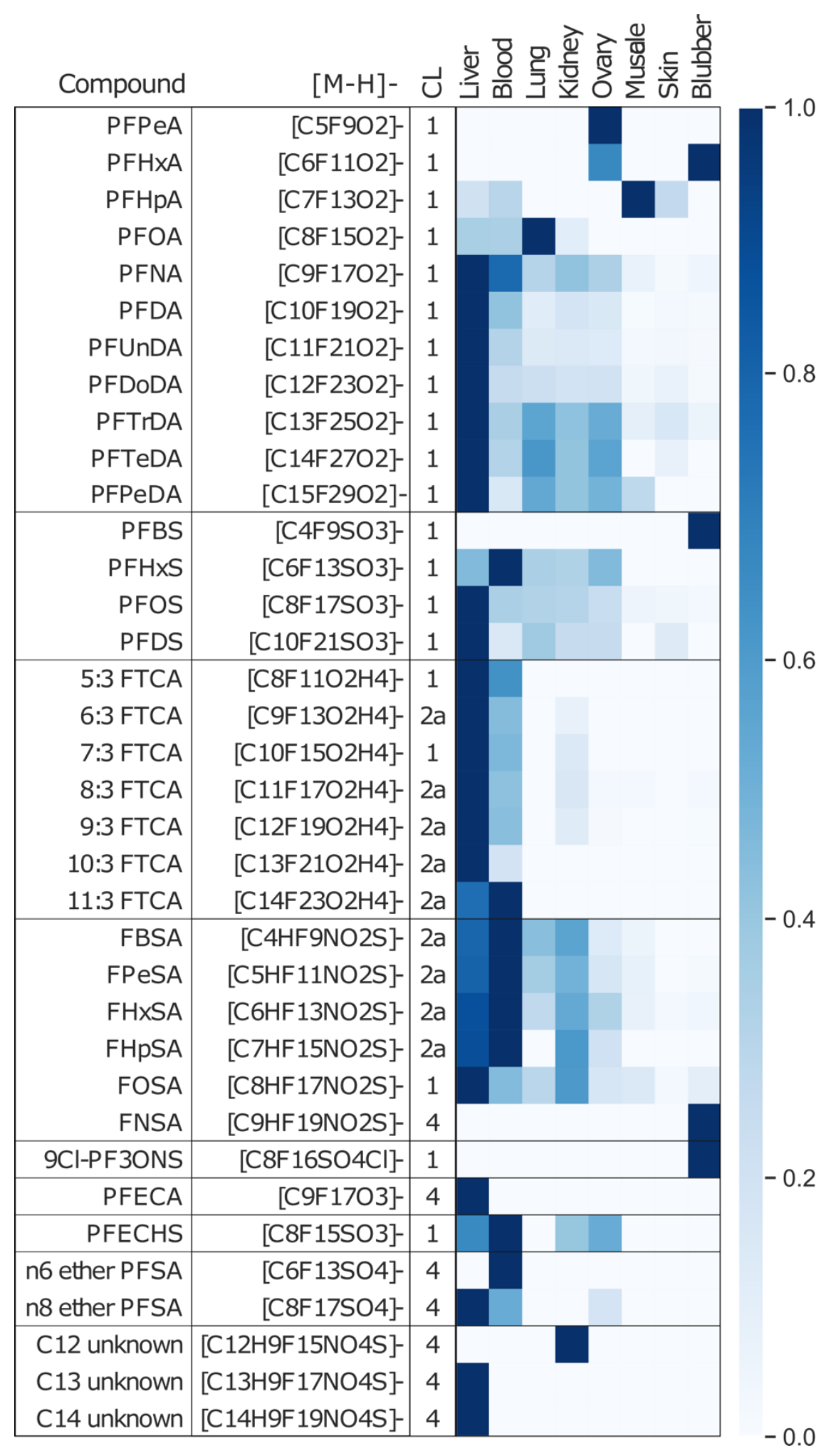

Figure 3. Tissue distribution heatmap showing relative intensities of target and suspect PFASs. Data are normalized to the most intense peak in a given tissue for each substance, facilitating compound-specific comparisons between tissues rather than between-compound comparisons. Confidence level (CL) are assigned according to Schymanski et al. ${ }^{22}$ 


\section{References}

(1) Houde, M.; Martin, J. W.; Letcher, R. J.; Solomon, K. R.; Muir, D. C. G. Biological Monitoring of Polyfluoroalkyl Substances: A Review. Environ. Sci. Technol. 2006, 40 (11), 3463-3473. https://doi.org/10.1021/es052580b.

(2) Benskin, J. P.; Muir, D. C. G.; Scott, B. F.; Spencer, C.; De Silva, A. O.; Kylin, H.; Martin, J. W.; Morris, A.; Lohmann, R.; Tomy, G.; et al. Perfluoroalkyl Acids in the Atlantic and Canadian Arctic Oceans. Environ. Sci. Technol. 2012, 46 (11), 5815-5823. https://doi.org/10.1021/es300578x.

(3) Rankin, K.; Mabury, S. A.; Jenkins, T. M.; Washington, J. W. A North American and Global Survey of Perfluoroalkyl Substances in Surface Soils: Distribution Patterns and Mode of Occurrence. Chemosphere 2016, 333-341. https://doi.org/10.1016/j.chemosphere.2016.06.109.

(4) KEMI Swedish Chemical Agency. Occurrence and Use of Highly Fluorinated Substances and Alternatives; 2015.

(5) Organisation for Economic Co-operation and Development. Toward a New Comprehensive Global Database of Per- and Polyfluoroalkyl Substances (PFASs): Summary Report on Updating the OECD 2007 List of per-and Polyfluoroalkyl Substances (PFASs) - OECD Environment, Health and Safety Publications Series on Risk Manag; 2018.

(6) Liu, Y.; Qian, M.; Ma, X.; Zhu, L.; Martin, J. W. Nontarget Mass Spectrometry Reveals New Perfluoroalkyl Substances in Fish from the Yangtze River and Tangxun Lake, China. Environ. Sci. Technol. 2018, 52 (10), 5830-5840. https://doi.org/10.1021/acs.est.8b00779.

(7) Liu, Y.; Richardson, E. S.; Derocher, A. E.; Lunn, N. J.; Lehmler, H. J.; Li, X.; Zhang, Y.; Cui, J. Y.; Cheng, L.; Martin, J. W. Hundreds of Unrecognized Halogenated Contaminants Discovered in Polar Bear Serum. Angew. Chemie - Int. Ed. 2018, 57 (50), 16401-16406. https://doi.org/10.1002/anie.201809906.

(8) Spaan, K. M.; Van Noordenburg, C.; Plassmann, M. M.; Schultes, L.; Shaw, S.; Berger, M.; Heide-Jørgensen, M. P.; Rosing-Asvid, A.; Granquist, S. M.; Dietz, R.; et al. Fluorine Mass Balance and Suspect Screening in Marine Mammals from the Northern Hemisphere. Environ. Sci. Technol. 2020, 54 (7), 4046-4058. https://doi.org/10.1021/acs.est.9b06773.

(9) Koch, A.; Aro, R.; Wang, T.; Yeung, L. W. Y. Towards a Comprehensive Analytical Workflow for the Chemical Characterisation of Organofluorine in Consumer Products and Environmental Samples. TrAC - Trends in Analytical Chemistry. Elsevier B.V. February 1, 2020. https://doi.org/10.1016/j.trac.2019.02.024.

(10) Loi, E. I. H. H.; Yeung, L. W. Y. Y.; Taniyasu, S.; Lam, P. K. S. S.; Kannan, K.; Yamashita, 
N. Trophic Magnification of Poly- and Perfluorinated Compounds in a Subtropical Food Web. Environ. Sci. Technol. 2011, 45 (13), 5506-5513. https://doi.org/10.1021/es200432n.

(11) Yeung, L. W. Y.; Miyake, Y.; Wang, Y.; Taniyasu, S.; Yamashita, N.; Lam, P. K. S. Total Fluorine, Extractable Organic Fluorine, Perfluorooctane Sulfonate and Other Related Fluorochemicals in Liver of Indo-Pacific Humpback Dolphins (Sousa Chinensis) and Finless Porpoises (Neophocaena Phocaenoides) from South China. Environ. Pollut. 2009, 157 (1), 17-23. https://doi.org/10.1016/j.envpol.2008.08.005.

(12) Taniyasu, S.; Senthilkumar, K.; Yamazaki, E.; Yeung, L. W. Y.; Guruge, K. S.; Kannan, K.; Yamashita, N. Perfluoroalkyl Substances in the Blood of Wild Rats and Mice from 47 Prefectures in Japan: Use of Samples from Nationwide Specimen Bank. Arch. Environ. Contam. Toxicol. 2013, 65 (1), 149-170. https://doi.org/10.1007/s00244-013-9878-4.

(13) Letcher, R. J.; Bustnes, J. O.; Dietz, R.; Jenssen, B. M.; Jørgensen, E. H.; Sonne, C.; Verreault, J.; Vijayan, M. M.; Gabrielsen, G. W. Exposure and Effects Assessment of Persistent Organohalogen Contaminants in Arctic Wildlife and Fish. Sci. Total Environ. 2010, 408 (15), 2995-3043. https://doi.org/10.1016/j.scitotenv.2009.10.038.

(14) Pedro, S.; Boba, C.; Dietz, R.; Sonne, C.; Rosing-Asvid, A.; Hansen, M.; Provatas, A.; McKinney, M. A. Blubber-Depth Distribution and Bioaccumulation of PCBs and Organochlorine Pesticides in Arctic-Invading Killer Whales. Sci. Total Environ. 2017, 601602, 237-246. https://doi.org/10.1016/j.scitotenv.2017.05.193.

(15) Krahn, M. M.; Hanson, M. B.; Baird, R. W.; Boyer, R. H.; Burrows, D. G.; Emmons, C. K.; Ford, J. K. B.; Jones, L. L.; Noren, D. P.; Ross, P. S.; et al. Persistent Organic Pollutants and Stable Isotopes in Biopsy Samples (2004/2006) from Southern Resident Killer Whales. Mar. Pollut. Bull. $\quad$ 2007, $54 \quad$ (12), 1903-1911. https://doi.org/10.1016/J.MARPOLBUL.2007.08.015.

(16) Schnitzler, J. G.; Reckendorf, A.; Pinzone, M.; Autenrieth, M.; Tiedemann, R.; Covaci, A.; Malarvannan, G.; Ruser, A.; Das, K.; Siebert, U. Supporting Evidence for PCB Pollution Threatening Global Killer Whale Population. Aquat. Toxicol. 2019, 206, 102-104. https://doi.org/10.1016/j.aquatox.2018.11.008.

(17) Gebbink, W. A.; Bossi, R.; Rigét, F. F.; Rosing-Asvid, A.; Sonne, C.; Dietz, R. Observation of Emerging Per- and Polyfluoroalkyl Substances (PFASs) in Greenland Marine Mammals. Chemosphere 2016, 144, 2384-2391. https://doi.org/10.1016/j.chemosphere.2015.10.116.

(18) Letcher, R. J.; Chu, S.; McKinney, M. A.; Tomy, G. T.; Sonne, C.; Dietz, R. Comparative Hepatic in Vitro Depletion and Metabolite Formation of Major Perfluorooctane Sulfonate Precursors in Arctic Polar Bear, Beluga Whale, and Ringed Seal. Chemosphere 2014, 112, 225-231. https://doi.org/10.1016/j.chemosphere.2014.04.022. 
(19) Galatius, A.; Bossi, R.; Sonne, C.; Rigét, F. F.; Kinze, C. C.; Lockyer, C.; Teilmann, J.; Dietz, R. PFAS Profiles in Three North Sea Top Predators: Metabolic Differences among Species? Environ. Sci. Pollut. Res. 2013, 20 (11), 8013-8020. https://doi.org/10.1007/s11356-013-1633-x.

(20) Schultes, L.; Vestergren, R.; Volkova, K.; Westberg, E.; Jacobson, T.; Benskin, J. P. Perand Polyfluoroalkyl Substances and Fluorine Mass Balance in Cosmetic Products from the Swedish Market: Implications for Environmental Emissions and Human Exposure. Environ. Sci. Process. Impacts 2018, $20 \quad$ (12), 1680-1690. https://doi.org/10.1039/c8em00368h.

(21) Miaz, L. T.; Plassmann, M. M.; Gyllenhammar, I.; Bignert, A.; Sandblom, O.; Lignell, S.; Glynn, A.; Benskin, J. P. Temporal Trends of Suspect- and Target-per/Polyfluoroalkyl Substances (PFAS), Extractable Organic Fluorine (EOF) and Total Fluorine (TF) in Pooled Serum from First-Time Mothers in Uppsala, Sweden, 1996-2017. Environ. Sci. Process. Impacts 2020. https://doi.org/10.1039/c9em00502a.

(22) Schymanski, E. L.; Jeon, J.; Gulde, R.; Fenner, K.; Ruff, M.; Singer, H. P.; Hollender, J. Identifying Small Molecules via High Resolution Mass Spectrometry: Communicating Confidence. Environmental Science and Technology. American Chemical Society February 18, 2014, pp 2097-2098. https://doi.org/10.1021/es5002105.

(23) Greaves, A. K.; Letcher, R. J.; Sonne, C.; Dietz, R.; Born, E. W. Tissue-Specific Concentrations and Patterns of Perfluoroalkyl Carboxylates and Sulfonates in East Greenland Polar Bears. Environ. Sci. Technol. 2012, 46 (21), 11575-11583. https://doi.org/10.1021/es303400f.

(24) Aas, C. B.; Fuglei, E.; Herzke, D.; Yoccoz, N. G.; Routti, H. Effect of Body Condition on Tissue Distribution of Perfluoroalkyl Substances (PFASs) in Arctic Fox (Vulpes Lagopus). Environ. Sci. Technol. 2014, 48 (19), 11654-11661. https://doi.org/10.1021/es503147n.

(25) Ahrens, L.; Siebert, U.; Ebinghaus, R. Total Body Burden and Tissue Distribution of Polyfluorinated Compounds in Harbor Seals (Phoca Vitulina) from the German Bight. Mar. Pollut. Bull. 2009, 58 (4), 520-525. https://doi.org/10.1016/j.marpolbul.2008.11.030.

(26) Van De Vijver, K. I.; Hoff, P.; Das, K.; Brasseur, S.; Van Dongen, W.; Esmans, E.; Reijnders, P.; Blust, R.; De Coen, W. Tissue Distribution of Perfluorinated Chemicals in Harbor Seals (Phoca Vitulina) from the Dutch Wadden Sea. Environ. Sci. Technol. 2005, 39 (18), 6978-6984. https://doi.org/10.1021/es050942+.

(27) Armitage, J. M.; Arnot, J. A.; Wania, F. Potential Role of Phospholipids in Determining the Internal Tissue Distribution of Perfluoroalkyl Acids in Biota. 2012. https://doi.org/10.1021/es304430r. 
(28) Dassuncao, C.; Pickard, H.; Pfohl, M.; Tokranov, A. K.; Li, M.; Mikkelsen, B.; Slitt, A.; Sunderland, E. M. Phospholipid Levels Predict the Tissue Distribution of Poly- and Perfluoroalkyl Substances in a Marine Mammal. Environ. Sci. Technol. Lett. 2019, 6 (3), 119-125. https://doi.org/10.1021/acs.estlett.9b00031.

(29) Nilsson, H.; Kärrman, A.; Rotander, A.; van Bavel, B.; Lindström, G.; Westberg, H. Biotransformation of Fluorotelomer Compound to Perfluorocarboxylates in Humans. Environ. Int. 2013, 51, 8-12. https://doi.org/10.1016/j.envint.2012.09.001.

(30) Powley, C. R.; George, S. W.; Russell, M. H.; Hoke, R. A.; Buck, R. C. Polyfluorinated Chemicals in a Spatially and Temporally Integrated Food Web in the Western Arctic. Chemosphere 2008, 70 (4), 664-672. https://doi.org/10.1016/j.chemosphere.2007.06.067.

(31) Persson, M. J. D. Levels of Perfluoroalkyl and Polyfluoroalkyl Substances (PFASs) in Feathers of Eurasian Eagle-Owls (Bubo Bubo) in Norway. Master Thesis, Norwegian University of Science and Technology., 2017.

(32) Nyberg, E.; Awad, R.; Bignert, A.; Ek, C.; Sallsten, G.; Benskin, J. P. Inter-Individual, Inter-City, and Temporal Trends of per- and Polyfluoroalkyl Substances in Human Milk from Swedish Mothers between 1972 and 2016. Environ. Sci. Process. Impacts 2018, 20 (8), 1136-1147. https://doi.org/10.1039/c8em00174j.

(33) Martin, J. W.; Smithwick, M. M.; Braune, B. M.; Hoekstra, P. F.; Muir, D. C. G.; Mabury, S. A. Identification of Long-Chain Perfluorinated Acids in Biota from the Canadian Arctic. Environ. Sci. Technol. 2004, 38 (2), 373-380. https://doi.org/10.1021/es034727+.

(34) Pedro, S.; Boba, C.; Dietz, R.; Sonne, C.; Rosing-Asvid, A.; Hansen, M.; Provatas, A.; McKinney, M. A. Blubber-Depth Distribution and Bioaccumulation of PCBs and Organochlorine Pesticides in Arctic-Invading Killer Whales. Sci. Total Environ. 2017, 601602, 237-246. https://doi.org/10.1016/j.scitotenv.2017.05.193.

(35) McHugh, B.; Law, R. J.; Allchin, C. R.; Rogan, E.; Murphy, S.; Foley, M. B.; Glynn, D.; McGovern, E. Bioaccumulation and Enantiomeric Profiling of Organochlorine Pesticides and Persistent Organic Pollutants in the Killer Whale (Orcinus Orca) from British and Irish Waters. Mar. Pollut. Bull. 2007, $54 \quad$ (11), 1724-1731. https://doi.org/10.1016/j.marpolbul.2007.07.004. 